\title{
ESTRESSE DA EQUIPE DE ENFERMAGEM DO CORPO DE BOMBEIROS NO ATENDIMENTO PRÉ-HOSPITALAR MÓVEL
}

\author{
Stress at the nursing staff from the fire department in a mobile pre-hospital care \\ El estrés del equipo de enfermería del cuerpo de bomberos en atención pre-hospitalaria \\ móvil
}

\section{RESUMO}

A pesquisa teve como objeto de estudo o estresse evidenciado no trabalho da equipe de Enfermagem do Corpo de Bombeiros no Atendimento Pré-Hospitalar Móvel. Os objetivos foram: identificar os estressores presentes nessa atividade profissional e analisar a repercussão do estresse na saúde desses profissionais.Caracterizou-se como um estudo qualitativo descritivo-exploratório, envolvendo 10 profissionais. A coleta de dados foi realizada por meio de entrevista gravada eletronicamente, utilizando-se de instrumento semiestruturado. Após transcrição das entrevistas, os aspectos semelhantes e as diferenças encontradas foram agrupados em Categorias de Análise. Confirmou-se que esses profissionais são submetidos a constante estresse, tendo seus hábitos de vida alterados, com repercussão na saúde. Sugere-se que os problemas identificados sejam estudados de maneira a criar estratégias com a finalidade de gerar melhores condições de trabalho para esses profissionais.

Palavras-chave: Estresse ocupacional. Saúde do trabalhador. Enfermagem. Assistência pré-hospitalar. Bombeiros.

\begin{abstract}
The research has as subject, the study of the stress at work on a nursing staff from the Fire Department in the pre - hospital care, and aims to identify what are the stressors in the work of professionals who are part of the nursing staff of APH Mobile from the Fire Department; analyze the impact of stress on the health of these professionals. The study characterized itself as qualitative descriptive - exploratory, involving 10 professionals. Data collection was conducted through interviews recorded electronically, using a semistructured instrument. After transcription of the interviews, the similar aspects and differences found were grouped into analyze categories. It was confirmed that these professionals are subjected to constant stress, having modified their lifestyle habits, with health impact. It is suggested that the identified problems are studied in order to develop strategies in order to generate better working conditions for these professionals.
\end{abstract}

Keywords: Burnout, Professional. Occupational Health. Nursing. Prehospital Care. Firemen.
Resumen

La presente investigación tiene como objeto de estudio analizar el estrés del trabajo del personal de enfermería del Cuerpo de Bomberos en la atención pre-hospitalaria móvil; y tiene por objetivos: determinar cuáles son los factores de estrés en el trabajo de estos profesionales; analizar el impacto del estrés sobre la salud. Caracterizado como un estudio cualitativo, descriptivo - exploratorio, con la participación de 10 profesionales. La recolección de datos se llevó a cabo a través de entrevistas grabadas por vía electrónica, utilizando un instrumento semiestructurado. Después de transcribir las entrevistas, los aspectos similares y las diferencias fueron agrupan en categorías y analizados según la luz del marco teórico. Se confirmó que estos trabajadores están sometidos a un estrés constante, teniendo sus hábitos de vida modificados, con repercusión en la salud. Se sugiere crear estrategias con el fin de crear mejores condiciones de trabajo para estos profesionales.

\footnotetext{
Enfermeira graduada pela Escola de Enfermagem Anna Nery da Universidade Federal do Rio de Janeiro (UFRJ). Mestranda do Núcleo de Pesquisa Enfermagem e Saúde do Trabalhador da Escola de Enfermagem Anna Nery/UFRJ. Rio de Janeiro-RJ. Brasil. E-mail: richiere@hotmail.com; ${ }^{2}$ Enfermeira. Mestre do Núcleo de Pesquisa Enfermagem e Saúde do Trabalhador, da Escola de Enfermagem Anna Nery/UFRJ. Major. CBMERJ Enfermeira. Rio de Janeiro-RJ. Brasil. E-mail: barbaragse@gmail.com;3Professora Associada do Departamento de Enfermagem Fundamental da Escola de Enfermagem Anna Nery/UFRJ. Doutora em Enfermagem. Membro do Núcleo de Pesquisa Enfermagem e Saúde do Trabalhador e Núcleo de Pesquisa de Fundamentos do Cuidado de Enfermagem. Rio de Janeiro-RJ. Brasil. E-mail: marcialis@terra.com.br.
} 


\section{INTRODUÇÃO}

Os profissionais da equipe de enfermagem do Corpo de Bombeiros, atuantes no Atendimento Pré-Hospitalar (APH) Móvel, estão em exposição constante a fatores estressantes. Fazem parte do seu cotidiano o estado permanente de prontidão, situações inusitadas, escalas desgastantes e o convívio com ambientes estressantes ${ }^{1}$. 0 objeto deste estudo é o estresse do trabalho da equipe de Enfermagem do Corpo de Bombeiros no Atendimento PréHospitalar (APH) Móvel.

No que diz respeito à relação entre estresse e trabalho, não é impossível constatar que o ser humano se depara hoje com um universo profissional que, comumente, faz exigências além da sua capacidade. Tal fato gera um constante estado de estresse entre os trabalhadores. Tratase do estresse de caráter ocupacional ${ }^{2}$. As doenças surgem quando a capacidade do indivíduo se esgota para, de forma saudável, responder ao trabalho. 0 estresse é reconhecido como um dos riscos mais sérios ao bem-estar psicossocial do indivíduo. Sua complexidade deve-se ao fato de o estresse organizacional pôr em risco a saúde, uma vez que 50 a $80 \%$ de todas as doenças têm fundo psicossomático ou estão relacionadas ao nível de estresse ${ }^{3}$.

Realizou-se também, para o fim acima descrito, pesquisa nas bases de dados da Biblioteca Virtual em Saúde, via descritores DeCS/MeSH. Restringiu-se a busca a trabalhos publicados nos últimos 10 anos, em português, inglês e espanhol. Foram encontradas 43 produções com os descritores Estresse Ocupacional e Enfermagem, sendo 37 delas localizadas na MEDLINE e 6 delas, na LILACS. Ao refinarmos, utilizando os descritores Assistência PréHospitalar e Bombeiros, não obtivemos resultado. Com outras combinações entre os descritores Bombeiro, estresse ocupacional, Assistência Pré-Hospitalar e Saúde do Trabalhador foram encontradas 4 publicações cujas abordagens estão próximas aos assuntos desta pesquisa. Embora o estresse ocupacional seja um tema pesquisado na área de Saúde do Trabalhador, existe uma importante lacuna do conhecimento no que se refere principalmente às relações entre estresse ocupacional e a enfermagem no APH.

A relevância deste estudo está ligada à oportunidade de se conhecer a relação que se estabelece entre o estresse, os profissionais da equipe de enfermagem do Corpo de Bombeiros e seu trabalho, o que possibilita, então, o estudo de estratégias eficazes para amenizá-lo, com repercussões positivas.

Assim sendo, os objetivos são: identificar os estressores presentes no trabalho dos profissionais que constituem a equipe de enfermagem do APH Móvel do Corpo de Bombeiros; e analisar a repercussão do estresse na saúde desses profissionais.

\section{REFERÊNCIA TEÓRICA}

Esta pesquisa adotou como referencial teórico as concepções de Hans Selye, que define estresse como "o estado manifestado por uma síndrome específica, constituído por todas as alterações não específicas produzidas num sistema biológico" "4:64. Portanto, o estresse possui características definidas, mas não uma causa delimitada, tendo a seguinte significação para o seu agente: "aquele que produz estresse $\mathrm{e}^{4: 77}$; é claro que qualquer agente poderá causar mais ou menos estresse, de acordo com sua capacidade de provocar alterações.

A Síndrome de Adaptação Geral (SAG) compreende "todas as alterações não espećficcas, na medida em que elas se desenvolvem no tempo, durante exposição contínua a um agente estressor" ":77. Uma SAG perfeita é formada por três fases: reação de alarme, fase de resistência e fase de exaustão. É muito difícil, no decorrer da vida, existir alguém que não passe pelas duas primeiras fases. Do contrário, não seria possível uma adaptação satisfatória para o desenvolvimento de todas as atividades da construção de resistência às infelicidades. 0 adoecimento pode ser consequência da incapacidade do corpo em adaptar-se $e^{4}$.

\section{MÉTODO}

0 estudo foi desenvolvido no $1^{\circ}$ semestre de 2010. Caracterizou-se como qualitativo descritivo-exploratório. Foi realizado no Grupamento de Bombeiro Militar do Estado do Rio de Janeiro, com 10 profissionais, sendo 6 do gênero masculino e 4 do feminino, 8 técnicos e 2 auxiliares de enfermagem atuantes no APH Móvel. Durante o período das entrevistas não foi possível entrevistar nenhum enfermeiro, pois estes sempre estavam em atuação. A pesquisa desenvolveuse após aprovação pelo CEP EEAN/HESFA protocolo número 008/2010 e com a devida assinatura dos sujeitos do Termo de Consentimento Livre e Esclarecido (TCLE). A coleta de dados foi realizada por meio de entrevista gravada em meio eletrônico, utilizando-se de um instrumento semiestruturado. As entrevistas foram identificadas pela letra "E" seguida do número correspondente à ordem de realização. Após a transcrição, os aspectos semelhantes e as diferenças encontradas foram agrupados em Categorias de Análise. Tal análise foi baseada na análise temática de Bardin, a partir dos recortes das falas dos sujeitos envolvidos. Foram construídas as seguintes unidades temáticas: estressores identificados e repercussão do estresse na saúde dos profissionais.

\section{RESULTADOS E DISCUSSÕES}

Verificou-se que não existe diferença considerável nas respostas dos entrevistados que pudesse ser atribuída a fatores como idade, sexo, patente, tempo de serviço na enfermagem ou no APH Móvel. 
0 principal estressor identificado nos relatos desses profissionais foi o Serviço de Atendimento Móvel de Urgência (SAMU) como atribuição do Corpo de Bombeiros, o que aconteceu após integração entre SAMU e CBM no Rio de Janeiro, o segundo coordenando o primeiro.

Para os sujeitos, o serviço tornou-se sobrecarregado, uma vez que após esta integração, além de atenderem às situações de socorro, próprias do Corpo de Bombeiros, precisam também realizar 0 atendimento às emergências domiciliares:

[...] Eu acho que estamos sobrecarregado, devido a uns eventos que estamos fazendo [...] que não eram do Corpo de Bombeiros e hoje em dia está sendo, que é o evento SAMU, que é domiciliar, dentro de casa, descer com paciente acamado, descer com paciente do quarto andar. Então sobrecarrega a coluna, a gente sente dores também [...]. Eu acho que está sobrecarregando, porque saiu do padrão do Corpo de Bombeiros (E5).

Outro estressor é o tipo de atendimento que esses profissionais vêm realizando nos eventos do SAMU. Segundo eles, esses atendimentos, para os quais estão sendo mandados em suas respectivas ambulâncias pela Central de Regulação, não se configuram como emergência, o que gera estresse:

[...] diarreia, coisa boba, uma dor de cabeça, uma verificação de pressão, a gente está saindo pra essas coisas. Os eventos não estão sendo bem regulados pela regulação médica SAMU. Então, acabam empurrando a gente pra tudo quanto é tipo de coisa. Parece que eles querem ver é atendimento, uma coisa bem política. Quantidade (E5).

[...] e a Regulação quer que a gente leve [...] e na verdade, muitas vezes não tem nenhuma emergência para levar, mas eles (Central de Regulação) querem que a gente leve e a gente fica fazendo papel de táxi para um problema que poderia e deveria ser resolvido no ambulatório, e não numa grande emergência. Eu acho que o que mais estressa é isso (E6).

Diante da insatisfação com a tipologia da assistência, eles atribuíram o estresse sofrido também à Central de Regulação dos eventos, por partir dela o direcionamento das ambulâncias, e por acreditarem que os eventos poderiam ser controlados de modo eficaz, evitando-se ao máximo a saída desnecessária das ambulâncias:

[...] Mas hoje [...], eu posso dizer que o maior nível de estresse é o atendimento pré-hospitalar em casa.
Até mesmo pelos tipos de atendimentos que a gente faz, coisas que a gente vê que realmente não têm necessidade de ambulância (E7).

O SAMU (um tipo de APH móvel com vários tipos de viaturas, equipes diferenciadas e um fluxograma de atendimento) foi criado para atender às urgências de natureza traumática, clínica, pediátrica, cirúrgica, gineco-obstétrica e de saúde mental da população, em qualquer lugar, seja residência, local de trabalho ou ainda via pública. Deve chamar o SAMU em casos como: problemas cardiorrespiratórios; intoxicação exógena; queimaduras graves; ocorrência de maus tratos; em trabalhos de parto, em que haja risco de morte da mãe ou do feto; tentativas de suicídio; crises hipertensivas; acidentes ou traumas com vítimas; afogamentos; choque elétrico; acidentes com produtos perigosos e na transferência inter-hospitalar de doentes com risco de morte ${ }^{5}$.

As falas dos entrevistados, anteriormente citadas, trazem preocupação relevante, na medida em que nos levam a pensar acerca do emprego das ambulâncias devidamente equipadas e com profissionais capacitados, sendo utilizadas para atender a uma demanda que foge à proposta do SAMU, mantendo-as fora de suas bases, enquanto situações emergenciais estão acontecendo.

Ocupa-se o serviço com situações não cabíveis, e, por conta disso, as situações emergenciais podem não ter 0 atendimento no tempo adequado:

[...] às vezes eu me sinto frustrado, porque de repente eu podia fazer uma coisa a mais e não fiz porque não tinha condições [...] eu fui atender uma dor de cabeça em Ramos, saí do Méier e fui para Ramos e uma pessoa foi assaltada aqui no Méier, foi baleada, então a pessoa veio a óbito, aí eu fiquei chateado, porque poderia estar aqui mais próximo e atendê-la [...]É isso aí que eu falo, ocorre constantemente isso aí (E1).

Chamados telefônicos falsos, os vulgos trotes, ou para casos não emergenciais têm como consequência um aumento no tempo que se destinaria à prestação de auxílio a vítimas que de fato necessitam de cuidados urgentes. Isso importa na medida em que se tem conhecimento de que 0 atendimento préhospitalar adequado diminui a morbimor talidade por eventos geradores de agravos: "O intervalo entre o evento traumático e 0 atendimento hospitalar pode deteriorar as condições da vítima, o que poderia influenciar no resultado final"::22.

Além disso, é possível perceber a frustração de alguns profissionais. Para eles, é como se tivessem sido preparados e treinados para atuar em determinadas situações e agora se veem exercendo suas atividades em outras, que eles não entendem como próprias do Corpo de Bombeiro. Assim, parece que seu trabalho está sendo banalizado ou inutilizado: 
[...] hoje eu acho um pouco estressante pela quantidade de coisas que a gente atende; às vezes, não têm tanta necessidade de ter esse atendimento que não é um atendimento emergencial. Isso aí causa um pouco de estresse, um pouco de cansaço tanto físico quanto mental, porque a gente se dedica, treina, estuda, para prestar um tipo de serviço e chega aqui de repente houve a fusão que houve, e a gente começa a atender as pessoas que não são relacionadas realmente à emergência préhospitalar [...] (E8).

A entrada do SAMU culmina no aumento da demanda para o APH do Corpo de Bombeiros, gerando sobrecarga e, por consequência, dificuldade para suprir todas as necessidades da população.

Embora os profissionais refiram que a maioria da população é sempre muito agradecida pelo socorro prestado e respeita 0 trabalho por eles desempenhado, ela também constitui um estressor. Isso se dá por vários motivos, dentre eles: a solicitação do serviço para situações que não correspondem ao perfil do atendimento; a elaboração de eventos falsos para conseguir o envio de uma viatura (ambulância); atitudes de ameaça aos profissionais:

[...]A população, com o tempo, foi adquirindo certo conhecimento e aí já pegaram a malícia de como conseguir levar um socorro de emergência para onde eles quiserem. De fato, não passam às vezes as informações reais do que está acontecendo, às vezes até mentem [...]. A população não tem essa consciência que ela está tirando uma viatura de socorro de uma pessoa que realmente está precisando $[\ldots]$ (E8).

Além disso, a própria relação entre profissionais e clientela, durante a tensão do socorro, em alguns momentos torna-se difícil:

[...] Tem gente que sempre está estressado, mas a gente procura entender que a vítima está lá (na frente dele), precisando de socorro. E deve estar estressado. Ver alguém atropelado, um familiar vai estar estressado [...] (E2).

No ambiente do atendimento à emergência e urgência, as pessoas se encontram tensas e fragilizadas devido à situação que está sendo vivenciada e por isso podem reagir com agressividade. Exercer o cuidado de maneira humanizada nessa situação de atendimento crítico de saúde constitui um desafio para a enfermagem ${ }^{7}$.
Como exemplo do mau uso do serviço pela população, segundo informações divulgadas pela Prefeitura Municipal de Niterói, em 2009, na Região Metropolitana II do Estado do Rio de Janeiro, o SAMU recebeu aproximadamente 190 mil ligações. Mas o que mais chama atenção é o número de trotes, cerca de 35 mil, e mais um grande número de outras chamadas que não tinham relação direta com 0 atendimento emergencial. Tais chamadas acabaram sobrecarregando os sistemas do SAMU, exigindo tempo e desgaste da equipe 8 .

Outro estressor importante é a questão da receptividade dos hospitais para com as vítimas e a equipe de bombeiros do GSE. Com base nos relatos dos entrevistados, caracterizamos como desgastante a relação que os hospitais estabelecem, podendo ser caracterizada como resistência, ou dificuldade, ocorrida com frequência nas grandes emergências, para o serviço do GSE deixar a vítima e ter a garantia da continuidade da assistência necessária.

Os bombeiros do GSE relatam os problemas que encontram ao darem entrada com paciente em uma grande emergência. Os hospitais estão sempre lotados, há falta de médico para receber o paciente e escassez de leito para que este possa ser transferido da maca da ambulância:

[...] Você entra num hospital, você não tem maca, o médico não quer aceitar o paciente, eles acham que você tem que estar disponível, mas você não está. [...] Você não pode chegar ao hospital e abandonar o paciente [...] você tem que passar o paciente $[\ldots](E 6)$.

Se não houver disponibilidade de leito no hospital, o paciente não poderá ficar no chão, permanecendo na maca utilizada durante o primeiro socorro, e, por consequência, como o material está sendo utilizado, os profissionais não podem deixar o hospital. Ou ainda, não há médico de determinada especialidade que possa receber a vítima. Tal situação acaba por prejudicar o tempo do atendimento a novos eventos:

Na grande maioria das vezes, nunca tem maca, não tem cadeira. Então, a gente faz um atendimento que fica duas, três, às vezes, quatro horas preso com o paciente lá, porque não tem maca. Aí entra colisão, vários tipos de acidente, a gente não tem ambulância pra socorrer, e, dependendo do grau de acidente que acontecer, a gente tem que ir até sem maca, socorrer sem maca (E4).

Ás vezes, eu pegava eventos lá em Realengo, vamos supor [...], uma hora da tarde, um evento de queda, com suspeita de TCE, eu ficava até dez horas da 
noite. Por quê? Procurando neurologista no Rio de Janeiro. [...] (E7).

Uma das causas possíveis que explicaria a falta de maca nos hospitais seria a superlotação dos mesmos. A superlotação que acontece nos serviços hospitalares de emergência é um problema mundial, caracterizado pela ocupação de todos os leitos; pacientes acamados, alocados nos corredores; espera por atendimento, ultrapassando a duração de uma hora; tensão da equipe assistencial e pressão para novos atendimentos ${ }^{9}$.

Os bombeiros do GSE identificaram também como fator de estresse a violência com a qual se deparam, principalmente quando precisam entrar em áreas consideradas de risco para atendimento a um chamado de socorro. 0 medo e a sensação de perigo iminente, as ameaças, deixam esses profissionais sob forte tensão, pois a própria integridade física e mental deles está em risco:

Fator de estresse são momentos que você tem que entrar em comunidades e acaba lidando com bandido, fica na mão deles. Praticamente se der mole, tu é agredido. [...]. Então, quando a gente sabe que é área de risco, a gente já sai um pouco com a adrenalina, meio [...] preocupada. Isso é importante. [...] (E5).

Em algumas favelas, dominadas por traficantes, a equipe de socorro não é bem-vinda e inclusive, por parte dos marginais, já foi declarada a insatisfação com a entrada da ambulância. No entanto, nessas localidades as pessoas também necessitam do serviço. Tal fato cria uma situação extremamente conflituosa. De um lado, a necessidade de proteger a integridade dos profissionais e, do outro, o direito dos cidadãos à assistência:

[...] Já tive situações aqui de chegar com a ambulância e a gente ser recebido à bala, já tive situações de ter que ouvir o bandido pagar pra gente, o marginal pagar: ameaçar, e a gente sem poder falar nada, porque ele já tinha dado o aviso que não queria ambulância lá dentro (E8).

Os estressores até aqui identificados pelos profissionais revelam o desencadeamento, principalmente, das duas primeiras fases da SAG, são elas: a fase de alarme, marcada pelas primeiras reações fisiológicas ao estressor, e a fase de resistência, quando o indivíduo se adapta ao estressor para conseguir sobreviver.

No que se refere à repercussão do estresse na saúde desses profissionais, podemos identificá-la por meio da análise dos hábitos de vida dos mesmos.

Em relação ao padrão de sono, os profissionais foram questionados sobre quantas horas costumam dormir por dia, de que maneira avaliam seu sono e se este é recuperador.
Ressaltamos que há uma distinção importante entre a qualidade do sono que eles têm no trabalho e o sono em suas casas.

Dos dez profissionais, seis disseram que costumam dormir aproximadamente oito horas por dia. 0 restante apresenta um padrão de sono inferior. Em dias no trabalho, não é possivel determinar o número de horas de sono, pois, segundo os profissionais, isso irá depender do plantão:

Oito horas, mas quando eu estou de serviço eu não sei. Em média, ou eu não posso dormir ou eu posso dormir bastante (E7).

Para cinco desses profissionais, dos quais dois dormem menos de oito horas/dia, o sono é considerado satisfatório, ou seja, acordam descansados, recuperados. Os cinco demais, dos quais três dormem cerca de oito horas/dia, dizem que a quantidade de horas que conseguem dormir não é suficiente para que se sintam descansados, ou nem sempre o é. Dois desses profissionais evidenciam que seu sono depende da carga de trabalho, e por possuírem um outro emprego além do Corpo de Bombeiros, a quantidade de horas que dormem não é satisfatória.

Quanto à avaliação do sono, seis profissionais o avaliam como sendo tranquilo. Em contrapartida, quatro profissionais apresentam um sono agitado, conturbado, no qual acordam muitas vezes, referindo até mesmo dificuldade para dormir:

Eu tenho um sono agitado. Às vezes, muito pesado e não é um sono que me dá descanso (E6).

Agora, em casa, tem noites que eu tenho um pouco de insônia, vou dormir tarde, fico tentando achar o sono e não consigo [...] (E8).

O sono é fundamental para a consolidação da memória, na visão binocular, na termorregulação, na conservação e restauração da energia ${ }^{10}$. Considerando essas importantes funções, entende-se que as perturbações do sono podem ocasionar prejuízos no funcionamento físico, ocupacional, cognitivo e social, comprometendo significativamente a qualidade de vida do indivíduo ${ }^{11}$.

De acordo com os bombeiros, o sono durante um dia de trabalho no Grupamento de Socorro de Emergência, responsável pelas atividades de $\mathrm{APH}$, não é tranquilo. $\mathrm{A}$ preocupação em atender prontamente a um novo chamado e a agitação dos eventos antecedidos faz com que estes profissionais estejam sob tensão, encontrando dificuldade para relaxar:

No quartel eu simplesmente fico de olho fechado, eu não relaxo, porque eu fico com medo de perder corrida. Na maioria das vezes nosso sono é 
interrompido, porque na maioria das vezes nós saímos de madrugada [...] (E9).

0 trabalho exige que esses profissionais se mantenham sempre em alerta. Isso pode ser representado pela fase de alarme, descrita na SAG por Selye, na qual, diante do estímulo estressor, ocorre liberação de adrenalina para promover as respostas imediatas do estresse.

É possível dizer que há uma grande variação na qualidade do sono desses profissionais, sabendo que sua carga de trabalho é de 24 horas a cada 48 horas.

Ao falarmos sobre hábitos alimentares, identificou-se que os profissionais fazem cerca de três a cinco refeições por dia. Em dias de trabalho, o número de refeições depende do tempo que terão disponível para se alimentar:

Aqui tem café da manhã, almoço, janta e ceia, última refeição da noite. E, à tarde, a gente costuma fazer um lanche por conta própria; quando dá, vai na padaria, compra, intera, mas nem sempre dá, se tá na rua. [...]. Tem horário, a hora do almoço aqui é de 11 às 13 horas, é o horário certo. Mas nós, da ambulância, não temos horário. Pode-se sair 11 horas e voltar 4 horas da tarde [Aí vai almoçar 4 horas da tarde], o que seria uma janta (E1).

Quando questionados sobre os tipos de alimentos que costumam comer, cinco mostraram ter uma alimentação mais balanceada e saudável do que os demais. Alguns referiram o consumo constante de salgados, refrigerantes, pizza, pão, biscoito:

Jantar já não é uma coisa que eu faço questão. Nos horários destinados à janta, ou eu como pizza, hambúrguer [...] fast food, lasanha, coca-cola, chocolate (E10).

De acordo com a fala desses profissionais, em casa eles conseguem ter uma alimentação mais saudável do que no trabalho:

Eu procuro, quando estou em casa, fazer uma alimentação mais balanceada, porque eu sei que aqui, além de na maioria das vezes a comida não estar muito boa, não tenho hora pra comer e, às vezes, a gente come besteira na rua [...] Aqui eu como muito mal, em casa eu como bem (E9).

Além disso, no trabalho, estes profissionais comem de acordo com o cardápio do dia, e nem sempre o oferecido é adequado, no que diz respeito a uma alimentação saudável:

Olha, minha alimentação, eu procuro ser o mais saudável possivel [...]. Não gosto muito de fritura, fritura eu como só, quando eu estou aqui, porque a gente não tem opção, éo cardápio, aí a gente tem que seguir o cardápio [...] (E8).

Intimamente ligados à inadequação alimentar estão problemas como deficiências nutricionais, infecç̃̃es e doenças crônicas não transmissíveis, que ainda são extremamente preocupantes dentro da realidade brasileira ${ }^{12}$.

Reconhecendo a importância da atividade física na manutenção de uma vida saudável, os entrevistados foram questionados a respeito da prática de exerćício. A maioria realiza a educação física no quartel, a qual acontece pela manhã, antes de assumirem as viaturas. Como os profissionais fazem atividade física apenas nos dias em que estão de serviço, torna-se difícil manter a regularidade aconselhável.

Para cinco dos entrevistados, a educação física no quartel é a única atividade que realizam. Dois não praticam qualquer tipo de exercício nem mesmo no quartel. Um profissional beneficia-se da musculação e atividade física no quartel. Um outro faz caminhada e exercícios abdominais e flexões, além disso, pratica atividade no quartel. E um profissional costuma correr, mas não participa dos exercícios físicos no quartel. As atividades geralmente escolhidas pelos profissionais militares durante a educação física no quartel são corrida e futebol:

A gente faz uma corridinha, joga um futebol, coisas que ficam na nossa liberdade de fazer. Eles não ficam cobrando, tem gente que não faz, tem gente que joga futebol, mas a maioria faz (E7).

Foi perguntado aos entrevistados se buscam atividades de lazer, já que estas constituem um mecanismo de liberação do estresse, uma forma de sair da rotina e estratégia para tirar o foco do trabalho. Os relatos seguintes confirmam tais informações:

Adoro. Na minha folga, eu quero esquecer que eu sou enfermeira, que eu sou bombeiro, que eu trabalho ali, que eu faço aquilo. Eu quero ir ao shopping, eu quero ir ao cinema, eu quero ver o mar. Eu quero ir pra tudo quanto élugar [...] (E10).

A maioria dos profissionais respondeu que procura lazer, ao menos uma vez por semana. Entre as suas escolhas estão: cinema, shopping, praia, teatro, momentos com a família, zoológico, pesca:

Busco, porque, se não, eu já teria surtado. Eu costumo ir ao cinema, gosto de ir ao teatro, sair pra jantar [...], procuro sair com meus amigos, ir à casa dos meus amigos pra conversar [...] (E9). 
Dois dos dez profissionais entrevistados não buscam ativamente atividades de lazer:

Ultimamente não. [...] criado na praia, eu estou há onze anos fora da praia, só de vez em quando que eu vou, mas eu estou me acostumando já com esse ritmo aqui. Então, o que dá pra fazer, vamos, dá. Não dá, eu não ligo. Não ligo mais. [...] É, se der pra gente ir, a gente vai, se não der, não faço mais aquela questão [...] (E4).

As atividades podem ser classificadas como: estratégias de "evitamento", que criam uma forma de aliviar o estresse por meio de mecanismos que conduzam à tentativa de esquecer os estressores, como, por exemplo, ir ao cinema, dormir, e estratégias de confronto indireto, utilizadas para atenuar o grau de tensão e não evitá-lo, a exemplo, as funções religiosas e práticas esportivas ${ }^{13}$.

Neste momento faz-se oportuno citar a fase de resistência da SAG, na qual ocorre adaptação ao estressor de forma que a resistência do organismo aumenta.

Quando questionados sobre a sua saúde, quatro profissionais disseram ter problemas de saúde: um profissional tinha Asma; uma profissional tinha hipertensão arterial; uma profissional teve câncer de colo de útero, leve hipertireoidismo e síndrome de burnout; e uma profissional apresentava urolitíase.

Analisando a relação entre o estresse e os problemas de saúde apresentados pelos sujeitos desta pesquisa, tornamse cabíveis algumas considerações.

Cotidianamente os indivíduos estão expostos ao estresse mental ou psicológico, e a capacidade de reagir a isso é uma resposta natural e que se faz necessária. Porém, uma reação exacerbada ao estresse psicológico os torna mais suscetíveis ao desenvolvimento da hipertensão arterial, a qual pode provocar problemas cardiovasculares e/ou morte súbita ${ }^{14}$.

Em relação ao câncer de colo do útero, um de seus fatores de risco é a imunossupressão. Sabe-se que o estresse em altos níveis pode ocasionar uma baixa na imunidade do indivíduo, contribuindo para a suscetibilidade a determinadas doenças.

No que se refere ao hipertireoidismo, este também constitui uma doença frequentemente causada pelo estresse, podendo manifestar-se após uma experiência mental entendida pelo indivíduo como chocante ${ }^{4}$.

a síndrome de burnout, a qual pode ser entendida como um transtorno adaptativo crônico ao estresse e que está ligada às exigências do trabalho, geralmente acomete pessoas que trabalham com o público, ou seja, profissionais que continuamente vivenciam contatos pessoais e emocionais ${ }^{15}$.

Entende-se que esses profissionais provavelmente atingiram a fase de exaustão da SAG, quando a resistência diminui devido à incapacidade de adaptação do organismo diante da exposição prolongada ao estressor. Tal fato leva à queda da imunidade, possibilitando o surgimento de doenças e seu agravamento.

Nos últimos dois meses que antecederam as entrevistas, metade dos profissionais entrevistados apresentou alguma doença, dor, ou ainda desconforto. Os problemas citados foram: lombalgia, dor no ombro, tendinite, dor abdominal frequente, dor causada por reação inflamatória por picada de inseto, e infecções:

Fiz uma tendinite, fiquei 28 dias em casa por causa da tendinite (E3).

Tive infecção gastrointestinal [...]. Isso porque eu tive uma em fevereiro, [...], aí tive essa outra em março, tive conjuntivite, tive a crise de rinite, pielonefrite e há uma semana foi quando eu parei de tomar o antibiótico da otite. Então, todas essas vezes eu baixo, pego licença para dar chance pra o meu corpo se recuperar [...]. Nos últimos dois meses, eu tive quatro doenças infecciosas, mais a retirada do câncer [...] (E9) - Não relatou tratamento quimioterápico ou radioterápico.

Em seu trabalho, os bombeiros do GSE precisam transportar pacientes para macas, socorrer vítimas em diversos locais, os quais, muitas vezes, não oferecem condições adequadas ao atendimento, dentre outras situações por eles vividas. Logo, determinados problemas, como a lombalgia e a tendinite são esperados.

Sabe-se que o estresse leva à secreção de ACTH, o qual estimula o córtex das suprarrenais, que vai produzir substâncias corticoides anti-inflamatórias. Tais substâncias destroem os glóbulos brancos do sangue, necessários tanto à imunidade quanto às reações de hipersensibilidade alérgica. Como consequência, as respostas imune e alérgica são inibidas. ${ }^{4}$ Tal mecanismo explica as repetidas infecções relatadas pela profissional entrevistada neste estudo (E9).

Quanto à capacidade de concentração, $40 \%$ dos militares entrevistados afirmaram ter algum tipo de dificuldade de concentração. Esta foi relacionada a alguns fatores, como privação do sono, estresse, excesso de trabalho ou de tarefas:

Muita dificuldade de concentração. Porque eu me sinto cansada e o cansaço me leva. Às vezes, estou estudando e acho a cama muito mais interessante. [...] Mas é muito complicado para eu me concentrar (E9). 
Em relação à memória, $70 \%$ dos entrevistados queixaram-se, dizendo que não é muito boa, é falha ou, ainda, péssima. Também relacionaram a falha da memória ao cansaço, às poucas horas de sono, a muito trabalho e ao estresse:

A memória não é muito boa, mas acho que é por conta desses muitos anos dormindo pouco, dessa coisa do estresse, trabalhando muito, acho que isso, além dos problemas normais da vida da gente, acaba dando [...] na memória (E3).

Desta forma, percebemos que o prejuízo da memória pode decorrer dos fatores aos quais esses profissionais são submetidos. Além disso, entendemos que isso pode interferir negativamente durante 0 trabalho no atendimento de emergência.

\section{CONCLUSÕES}

Constatou-se com a pesquisa que a equipe de enfermagem do APH do CBM é submetida a constante estresse, tendo seus hábitos de vida alterados com repercussão na saúde. Entre os principais estressores identificados, destacam-se: a integração entre SAMU e CBM e, ainda, o atendimento a situações que não se caracterizam como emergências ou urgências, ou seja, que fogem à proposta dos serviços; e a receptividade dos grandes hospitais de emergência. Quanto à repercussão na saúde dos profissionais, destacam-se alterações no padrão de sono, problemas de saúde/ doenças e prejuízos à memória e à capacidade de concentração. Foi identificado que este grupo de trabalhadores precisa ser cuidado e melhor estudado pela enfermagem. Sugere-se que os problemas identificados sejam estudados de maneira a criar estratégias com a finalidade de gerar melhores condições de trabalho para esses profissionais. Essas estratégias, tanto do ponto de vista dos gestores como dos próprios trabalhadores, possibilitarão uma melhor prestação de cuidado à sua saúde, preservando sua integridade mental.

\section{REFERÊNCIAS}

1. Gonzales RMB, Donaduzzi JC, BeckCLC, Stekel LMCS. 0 estado de alerta: um estudo exploratório com o Corpo de Bombeiros. Esc. Anna Nery Rev. Enferm.2006 dez.; 10 (3): 370-7.

2. González EIR. Estresse ocupacional: Proteção Jurídica à saúde do trabalhador brasileiro [Dissertação]. Florianópolis (SC): Centro de Ciências Jurídicas, Universidade Federal de Santa Catarina; 2007.
3. Rossi AM. Estressores ocupacionais e diferenças de gênero. In: Rossi AM, Perrwé PL, Sauter SL, organizadores. Stress e qualidade de vida no trabalho: perspectivas atuais da saúde ocupacional. São Paulo: Átlas; 2005.

4. Selye H. Stress: A tensão da vida. Tradução de Frederico Branco. São Paulo: IBRASA; 1959, p. 64-77.

5. Ministério da Saúde (Brasil). Serviço de Atendimento Móvel de Urgência -SAMU 192. Disponível em: <http://portal.saude.gov.br/portal/saude/ area.cfm?id_area $=456>$.

6. Dalcin RR, Cavazzola LT. Serviço de assistência médica de urgência. In: Nasi LA, organizador. Rotinas em pronto-socorro. 2. ed. Porto Alegre(RS): Artmed; 2004.

7. Pai DD, Lautert L. Suporte humanizado no Pronto Socorro: um desafio para enfermagem. REBEN. 2005 mar.; 58(2): 231-4.

8. Prefeitura de Niterói (Rio de Janeiro). Trotes atrapalham atendimento do SAMU. Disponível em: <http://www.niteroi.rj.gov.br/novo/index.php/ component/content/article/420-trotes-atrapaham-atendimento-dosamu>.

9. Bittencourt RJ, Hortale VA. Intervenções para solucionar a superlotação nos serviços de emergência hospitalar: uma revisão sistemática. Cad. saúde pública. 2009 jul; 25(7): 1439-54.

10. Cardoso HC, Bueno FCC, Matar JC, Alves APR, Jochims I, Filho IHRV et al. Avaliação da qualidade do sono em estudantes de medicina. Revista Brasileira de Educação Médica. 2009 set; 33(3): 349-55.

11. Muller MR, Guimarães SS. Impacto dos transtornos do sono sobre o funcionamento diário e a qualidade de vida. Estud. psicol. (Campinas). 2007 out./dez; 24(4): 519-28.

12. Ministério da Saúde (Brasil). Guia alimentar para a população brasileira: promovendo a alimentação saudável. Brasília(DF): Editora MS, 2005.

13. Nascimento KC, Erdmann AL, Campos JC, Rosa MC. Percepções acerca do estresse no trabalho de uma equipe de atendimento Pré-Hospitalar. Revista Baiana de Enfermagem. 2007 maio-dez; 21(2-3): 9-17.

14. Nóbrega ACL, Castro RRT, Souza AC. Estresse mental e hipertensão arterial sistêmica. Rev. bras. hipertens. 2007 abr.jun.; 14(2): 94-97.

15. Moreira DS, Magnago RF, Sakae TM, Magajewski FRL. Prevalência da Síndrome de Burnout em trabalhadores de enfermagem de um hospital de grande porte da região sul do Brasil. Cad. saúde pública. 2009 jul.; 25(7): 1559-68. 